\title{
Quantitative Analysis of Punctate White Matter Lesions in Neonates Using Quantitative Susceptibility Mapping and R2* Relaxation
}

\author{
(D). Zhang, (D) A. Rauscher, (D) C. Kames, and (D)A.M. Weber
}

\begin{abstract}
BACKGROUND AND PURPOSE: It is difficult to distinguish punctate white matter lesions from focal hemorrhagic lesions in neonates on conventional MR imaging because both kinds of lesions show increased signal intensity on Tl-weighted images and, frequently, decreased signal intensity on T2-weighted images. Our aim was to distinguish punctate white matter lesions and focal hemorrhagic lesions using quantitative measures.
\end{abstract}

MATERIALS AND METHODS: In the current study, we acquired multiecho gradient recalled-echo MR imaging data from 24 neonates with hypoxic-ischemic encephalopathy and postprocessed them as R2* relaxation maps and quantitative susceptibility maps. Seven subjects who were found to have multifocal punctate white matter lesions and/or focal hemorrhagic lesions on R2* maps were included (mean gestational age at birth, $33 \pm 4.28$ weeks; mean gestational age at scanning, $38 \pm 2$ weeks). Manually drawing ROIs on R2* maps, we measured R2* and magnetic susceptibility values of the lesions, along with white matter regions within the corpus callosum as healthy comparison tissue.

RESULTS: R2* and magnetic susceptibility values were both found to easily distinguish punctate white matter lesions, focal hemorrhagic lesions, and healthy white matter tissue from each other $(P<.05)$, with a large Hedge g. R2* and magnetic susceptibility values were significantly increased in focal hemorrhagic lesions compared with punctate white matter lesions and healthy white matter tissue. Punctate white matter lesions were also found to have significantly increased values over healthy white matter tissue.

CONCLUSIONS: R2* and quantitative susceptibility maps can be used to help clinicians distinguish and measure focal hemorrhages, punctate white matter lesions, and healthy white matter tissue.

ABBREVIATIONS: GRE = gradient recalled-echo; $\mathrm{PWML}=$ punctate white matter lesion; $\mathrm{QSM}$ = quantitative susceptibility mapping

W ith benefits that come with improved neonatal intensive care, an increasing number of preterm neonates are surviving with reduced cystic periventricular leukomalacia and periventricular hemorrhagic infarction, which can be diagnosed by sonography. ${ }^{1,2}$ However, developmental outcomes following preterm birth remain poor, with 5\%-10\% having major motor def-

Received December 14, 2018; accepted after revision April 29, 2019.

From the Department of Radiology (Y.Z.) and Ministry of Education Key Laboratory of Child Development and Disorders (Y.Z.), Children's Hospital of Chongqing Medical University, Chongqing, P.R. China; Key Laboratory of Pediatrics in

Chongqing (Y.Z.), Chongqing, P.R. China; Chongqing International Science and Technology Cooperation Center for Child Development and Disorders (Y.Z.), Chongqing, P.R. China; and Division of Neurology (A.R., A.M.W.), Department of Pediatrics, University of British Columbia MRI Research Centre (A.R., A.M.W., C.K.), and Departments of Radiology, (A.R.) and Physics and Astronomy (C.K.), University of British Columbia, Vancouver, British Columbia, Canada.

Please address correspondence to Alexander Mark Weber, PhD, MSc, UBC MRI Research Centre, University of British Columbia, M10-Purdy Pavilion, 2221 Wesbrook Mall, Vancouver, BC V6T 2B5; e-mail: alex.weber@ubc.ca; @rauscherMRI

http://dx.doi.org/10.3174/ajnr.A6114 icits and more than half developing cognitive, behavioral, and social difficulties later in life.,

Noncystic punctate white matter lesions (PWMLs) are detected by MR imaging in one-third of preterm neonates and are not accurately detected by sonography. ${ }^{5-9}$ Histologic and MR imaging studies suggest that PWMLs have intense macrophage and microglial infiltration and reduced astroglia, which coincide with microscopic necrosis and early gliosis. ${ }^{10,11}$ Whether these multifocal PWMLs in neonatal brain injuries are associated with neurodevelopmental outcomes is still a matter of debate. ${ }^{12-15}$

The etiology of PWMLs remains unclear. Only sporadic reports exist of neonates presenting with perinatal asphyxia ${ }^{16-18}$ or convulsions $^{19}$ accompanied by similar white matter lesions. Cornette et $\mathrm{al}^{15}$ reported the MR imaging characteristics and neurodevelopmental outcomes of PWMLs in a large cohort of preterm and term neonates and found that these lesions were pre- 
dominantly associated with preterm birth but could also be seen in term infants.

PWMLs were defined as foci of T1- and T2-weighted hypointensity with no evidence of cystic degeneration. ${ }^{8,20}$ Previous MR imaging studies investigating PWMLs have been based on T1weighted images, which have primarily evaluated the lesions by their number, diameter, and location. ${ }^{13,20,21}$ A grading system on MR imaging was developed to classify white matter abnormalities as normal (no periventricular white matter lesions), minimal ( $\leq 3$ areas of T1-weighted signal abnormalities measuring $<2 \mathrm{~mm}$ ), moderate ( $>3$ areas of T1-weighted signal abnormalities or areas measuring $<2 \mathrm{~mm}$ but $<5 \%$ of the hemisphere involved), and severe (T1-weighted signal abnormalities involving $>5 \%$ of the hemisphere). ${ }^{8,13}$ The degree of signal intensity of these lesions, however, is underestimated, which, in turn, is likely to result in a misdiagnosis of the degree of injury. On the other hand, it is difficult to distinguish PWMLs from focal hemorrhage on conventional MR imaging because both kinds of lesions show increased signal intensity on T1-weighted images and frequently decreased signal on T2-weighted images. ${ }^{22,23}$ Accurate predictive tools are essential for clinicians to identify and quantify brain injury and provide early interventions to improve clinical outcomes of these neonates. $^{21}$

$\mathrm{R} 2^{*}$ mapping is a semiquantitative technique derived from multiecho gradient recalled-echo (GRE) MR imaging scans. R2* values are influenced by iron and myelin content and are relatively easy to calculate. ${ }^{24}$ Quantitative susceptibility mapping (QSM), on the other hand, is a newer technique and can be derived from the same scan as $\mathrm{R}^{*}$ (or from a more common single-echo GRE scan) but which fully quantifies magnetic susceptibility using the phase data of the scan. ${ }^{25}$ QSM has, until recently, been difficult to calculate, due to the ill-posed inverse field-to-susceptibility problem. In the current study, we acquired multiecho GRE scans in both preterm and term neonates to investigate PWML injuries with R2* and QSM maps. We hypothesized that these GRE-based MR imaging maps would allow us to distinguish PWMLs from hemorrhagic lesions with higher precision than conventional MR imaging scans.

\section{MATERIALS AND METHODS}

\section{Patients}

Between January 2017 and January 2018, preterm and term neonates with a clinical history of perinatal asphyxia and hypoxic-ischemic encephalopathy who transferred to the Children's Hospital of Chongqing Medical University intensive care nursery were approached for enrollment in a study evaluating the detection of brain injury by MR imaging. The institutional review board of Children's Hospital of Chongqing Medical University approved the study protocol, and informed consent was obtained from the parents. In total, 24 neonates were initially examined. The diagnostic criteria for PWMLs was foci of T1- and T2-weighted hypointensity with no evidence of cystic degeneration. ${ }^{8,20}$ Patients with T1 and T2 abnormalities were identified by 2 pediatric radiologists as part of the routine radiologic assessment, and any discrepancies were resolved through consensus. Eight neonates were found to have multifocal PWMLs and/or focal hemorrhagic lesions and were included for further study.

\section{MR Imaging Acquisition}

Brain MR images were obtained on a 3T system (Achieva; Philips Healthcare, Best, the Netherlands) using an 8-channel sensitivity encoding head coil. Data for R2* mapping and QSM were collected using a 3D GRE sequence with 5 echoes $(\mathrm{TR}=30 \mathrm{~ms}$, $\mathrm{TE}_{1}=4.5 \mathrm{~ms}$, echo spacing $=5.5 \mathrm{~ms}, \alpha=17^{\circ}, \mathrm{FOV}=196 \times$ $154 \times 103 \mathrm{~mm}^{3}$, acquired voxel size $=0.50 \times 0.75 \times 1.0 \mathrm{~mm}^{3}$, reconstructed voxel size $\left.=0.5 \times 0.5 \times 0.5 \mathrm{~mm}^{3}\right)$. ${ }^{26}$ Other scans included the following: inversion recovery turbo spin-echo T1weighting $(\mathrm{TR} / \mathrm{TI}=7000 / 600 \mathrm{~ms}, \mathrm{TE}=15 \mathrm{~ms}$, slice thickness $=$ $5 \mathrm{~mm}, \mathrm{FOV}=160 \times 151 \times 98 \mathrm{~mm}^{3}$, acquisition matrix $=220 \times$ 163 ); and turbo spin-echo T2-weighting ( $\mathrm{TR}=5000 \mathrm{~ms}$, $\mathrm{TE}=$ $100 \mathrm{~ms}$, slice thickness $=5 \mathrm{~mm}, \mathrm{FOV}=160 \times 149 \times 98 \mathrm{~mm}^{3}$, acquisition matrix $=332 \times 205$ ). Total acquisition time was 9 minutes 39 seconds.

\section{MR Image Analysis}

$\mathrm{R} 2{ }^{\star}$ maps were calculated from the multi-GRE scans by fitting a monoexponential function to the magnitude signal decay in each voxel. QSM images of all 5 echoes were postprocessed from the phase data. Phase unwrapping was achieved using a 3D Laplacian algorithm, ${ }^{27}$ while the background field was removed using the variable-kernel sophisticated harmonic artifact reduction for phase method. ${ }^{28}$ Last, a Gaussian filter ( $\sigma=$ 0.5 ) was applied to the normalized field maps to smooth out high-frequency errors originating from the reconstruction steps before the inversion. A 2-step dipole inversion algorithm ${ }^{29}$ was used to solve the dipole inversion problem. Finally, QSM images were then averaged across the third, fourth, and fifth echoes.

Authors Y.Z. and A.R. drew the ROIs independently. Neonates with scans with high motion or image artifacts were excluded. 3D ROIs encompassing PWMLs and focal hemorrhagic lesions were defined manually on consecutive slices of the R2* maps. Three ROIs of each subject were defined within the corpus callosum as normal white matter. For each ROI, the R2* and magnetic susceptibility values were measured.

\section{Statistical Analysis}

Statistical analysis was performed using R statistical and computing software (http://www.r-project.org). To assess interrater reliability, we calculated a 1-way intraclass correlation coefficient from the full set of $\mathrm{R} 2^{\star}$ and QSM values obtained from the 2 different observers' ROIs. Due to the small sample size, a nonparametric Kruskal-Wallis rank sum test was used to test differences of $\mathrm{R} 2^{*}$ and magnetic susceptibility values among the different tissue types. Post hoc Dunn tests were performed with Holm-Bonferonni correction for multiple comparisons to test differences among the different tissue types (Tables 1 and 2). The Hedge g was used to estimate effect size.

\section{RESULTS}

In total, 8 subjects were found to have multifocal PWMLs and/or focal hemorrhagic lesions on $\mathrm{R} 2^{\star}$ maps, with 1 patient with large 
MR imaging artifacts being excluded. This resulted in 7 subjects being used (mean gestational age at birth, $33 \pm 4.28$ weeks; mean gestational age at scanning, $38 \pm 2$ weeks). Of these 7 subjects, 5 were preterm (Table 3 ).

In all, 18 PWMLs, 9 focal hemorrhagic lesions, and 21 normal white matter ROIs (3 ROIs within the corpus callosum of each subject) were identified in the 7 subjects we examined (Table 3 and Fig 1). PWMLs in preterm infants are usually linearly organized along the periventricular white matter. The PWMLs in term infants and focal hemorrhagic lesions are relatively isolated in the white matter.

The interclass correlation coefficient for the values obtained from the 2 observers' ROIs was calculated to be 0.98 , which is defined as excellent by Koo and $\mathrm{Li}^{30}$

The $2^{\star}$ and magnetic susceptibility values for the 3 tissue types for each subject are shown in Fig 2. R2* and magnetic susceptibility boxplots are shown in Fig 3. The means and SDs of R2* and magnetic susceptibility values of the ROIs within the corpus callosum, PWMLs, and focal hemorrhagic lesions are listed in Table 4. The R2* and magnetic susceptibility values were found to be significantly different $(P<.05)$, with a large Hedge g, among all 3 regions.

\section{DISCUSSION}

Paramagnetic hemorrhagic products substantially increase $\mathrm{R} 2{ }^{*}$ relaxation rates and magnetic susceptibility. ${ }^{31,32}$ In our study, we have shown that $\mathrm{R} 2^{*}$ and magnetic susceptibility values of focal hemorrhagic lesions were significantly increased compared with PWMLs. Due to the magnetic susceptibility effect, signal increases indicating hemorrhage on R2*

Table 1: R2*-Dunn Kruskal-Wallis multiple comparisons ${ }^{\text {a }}$

\begin{tabular}{lccr}
\hline Comparison & $\boldsymbol{Z}$ & P.unadj & \multicolumn{1}{c}{ P.adj } \\
\hline CC FH & -5.88 & $4.05 \mathrm{e}-09$ & $1.21 \mathrm{e}-08$ \\
CC PWML & -4.24 & $2.19 \mathrm{e}-05$ & $4.38 \mathrm{e}-05$ \\
FH PWML & 2.40 & $1.64 \mathrm{e}-02$ & $1.64 \mathrm{e}-02$ \\
\hline
\end{tabular}

Note:- $P$.unadj indicates unadjusted P values; P.adj, adjusted P values; $C$, corpus callosum; FH, focal hemorrhagic lesion.

a $P$ values were adjusted using the Bonferroni-Holm correction for multiple comparisons.

Table 2: QSM-Dunn Kruskal-Wallis multiple comparisons ${ }^{\mathrm{a}}$

\begin{tabular}{lccc}
\hline Comparison & $\boldsymbol{Z}$ & P.unadj & P.adj \\
\hline CC FH & -5.70 & $1.19 \mathrm{e}-08$ & $3.58 \mathrm{e}-08$ \\
CC PWML & -3.75 & $1.75 \mathrm{e}-04$ & $3.50 \mathrm{e}-04$ \\
FH PWML & 2.61 & $9.04 \mathrm{e}-03$ & $9.04 \mathrm{e}-03$ \\
\hline
\end{tabular}

Note:-P.unadj indicates unadjusted $P$ values; P.adj, adjusted $P$ values; $C C$, corpus callosum; FH, focal hemorrhagic lesion.

a $P$ values were adjusted using the Bonferroni-Holm correction for multiple comparisons.

Table 3: Clinical data and MR imaging findings in the study population

\begin{tabular}{|c|c|c|c|c|c|c|c|c|}
\hline No. & $\begin{array}{c}\text { GA (Birth) } \\
\text { (wk) }\end{array}$ & $\begin{array}{l}\text { BW } \\
\text { (g) }\end{array}$ & Apgar & Sex & $\begin{array}{c}\text { Scan Age } \\
\text { (wk) }\end{array}$ & PWML & FH & IVH \\
\hline 1 & 39 & 3750 & 7 & Male & 41 & 2 & 2 & Yes \\
\hline 2 & 38 & 3645 & 7 & Male & 40 & 4 & 2 & Yes \\
\hline 3 & 31 & 1508 & 4 & Female & 37 & 8 & 0 & No \\
\hline 4 & 28 & 1210 & 6 & Female & 37 & 2 & 1 & Yes \\
\hline 5 & 29 & 1100 & 8 & Female & 35 & 2 & 0 & No \\
\hline 6 & 35 & 2770 & 9 & Male & 38 & 0 & 2 & No \\
\hline 7 & 34 & 1425 & 7 & Female & 38 & 0 & 2 & No \\
\hline
\end{tabular}

Note:-GA indicates gestational age; BW, birth weight; Apgar, Apgar score (5 minutes); IVH, presence of intraventricular hemorrhage; $\mathrm{FH}$, focal hemorrhagic lesion. maps appear to be larger compared with the actual hyperintense signal area on T1-weighted images. In follow-up studies, hemorrhagic lesions can be absorbed and no longer seen on conventional scans, whereas PWMLs, which may represent early gliosis and evolve into early glial scars, can still be present. ${ }^{22}$ In a previous study, some PWMLs on T1-weighted scans of preterm neonates were absent or decreased near termequivalent age, whereas others were worse on follow-up scans. ${ }^{23}$ Thus, changes in R2* and magnetic susceptibility may provide a biomarker of PWML progression.

Previous MR imaging studies have been based on T1-weighted images evaluating PWMLs by features such as the number, diameter, and location of lesions. ${ }^{13,20,21}$ The signal intensity of these lesions, however, is likely underestimated ${ }^{13-15}$; this underestimation may result in a misdiagnosis of injury. For example, while Jeon et $\mathrm{al}^{12}$ found that punctate lesions were significant predictors of cerebral palsy and Miller et $\mathrm{al}^{13}$ found that punctate lesions predicted a higher risk of neurodevelopmental disabilities, Dyet et $\mathrm{al}^{14}$ found that there were no significant differences in developmental outcomes between infants with and without PWMLs. Furthermore, Cornette et $\mathrm{al}^{15}$ found that isolated punctate lesions might imply a good prognosis because most subjects had a normal neurodevelopmental outcome at 29.5 months of age. It is difficult to distinguish PWMLs from focal hemorrhagic lesions on conventional MR imaging because both kinds of lesions show increased signal intensity on T1-weighted images and frequently decreased signal on T2-weighted images. ${ }^{22,23}$

From the results we obtained, $\mathrm{R} 2^{\star}$ and magnetic susceptibility values were able to easily distinguish healthy WM, PWMLs, and focal hemorrhagic lesions from each other. The R2* and magnetic susceptibility values of the PWMLs ranged from 9.76 to $17.06 \mathrm{~Hz}$ and from 0.002 to $0.035 \mathrm{ppm}$, respectively, which may be caused by the different disease stage and injury degree. The $\mathrm{R} 2 *$ and susceptibility values of the focal hemorrhagic lesions showed an even greater range, from 30.42 to $65.94 \mathrm{~Hz}$ and from 0.085 to 0.209 ppm, respectively. A large sample size and follow-up of the neonates is in progress, and it will be of interest to see whether there is a difference in outcome in those neonates with different R2* and magnetic susceptibility values of PWMLs.

While both R2* and QSM show great promise in measuring and differentiating PWMLs and focal hemorrhagic lesions, methodologic pros and cons should be weighed and discussed. R2* has historically been easier to postprocess because it requires simpler and fewer steps than QSM. Recently, however, QSM is becoming more mainstream, with wide dissemination possibly becoming feasible in the very near future. ${ }^{33} \mathrm{R} 2^{\star}$, unlike QSM, may have confounding factors such as fat, fibrosis, and edema ${ }^{33}$ and saturation and blooming artifacts. For instance, QSM, compared with $\mathrm{R} 2{ }^{*}$, has been shown to be more sensitive in identifying increased nigral iron in patients with Parkinson disease compared with healthy controls, ${ }^{34}$ to have a superior contrast-tonoise ratio in locating and identifying the subthalamic nuclei, ${ }^{35}$ and to be better at determining iron concentration of 

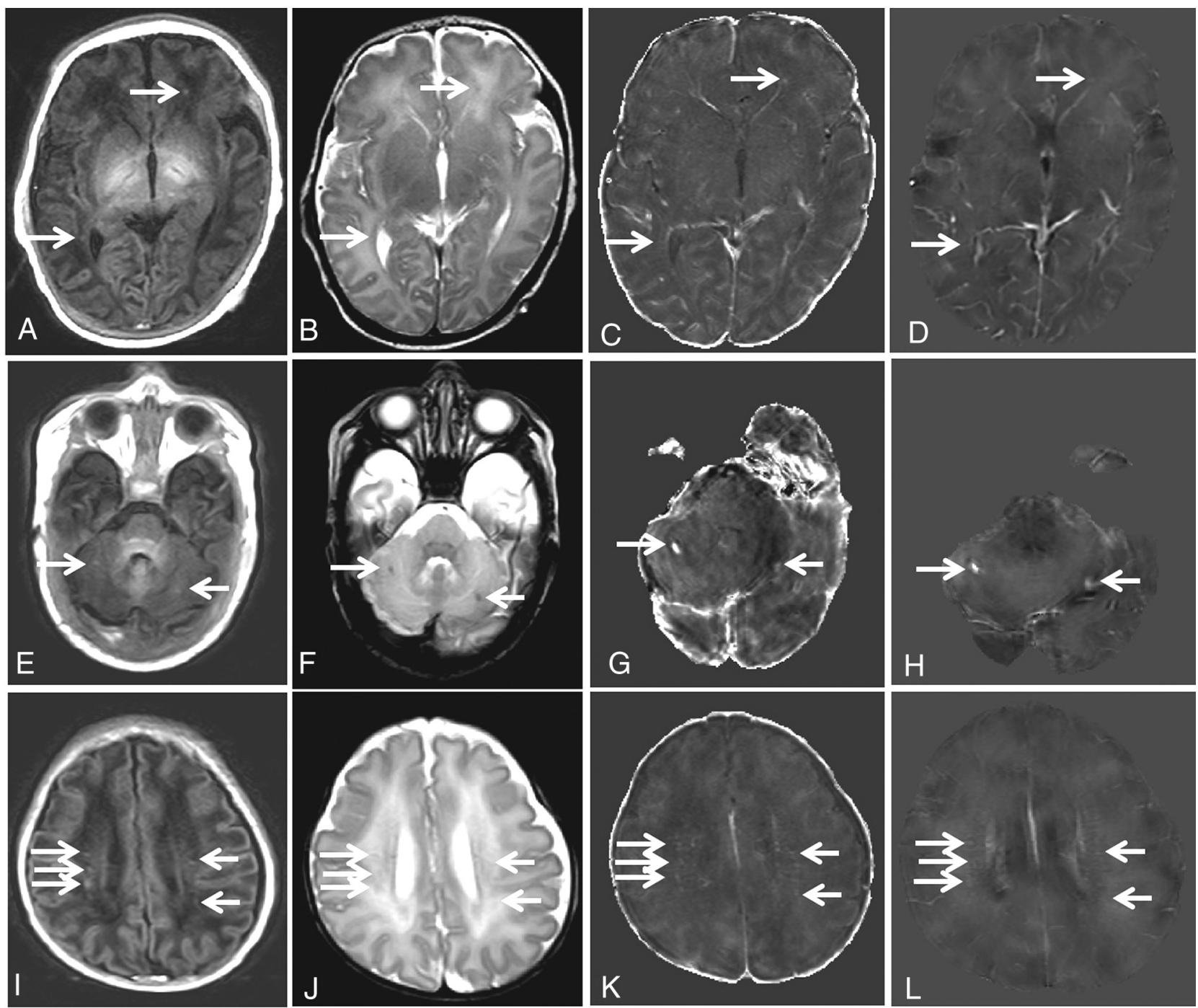

FIG 1. $A-D$, Punctate white matter lesions in a term neonate born at 38 weeks' gestational age, scanned at 40 weeks' gestational age (corresponding to case 2 in Table 3). A, Tl-weighted axial image shows isolated high-intensity spots (arrows) corresponding to punctate white matter lesions in the white matter of the left frontal lobe and right posterior periventricular white matter. $B$, Corresponding T2-weighted axial image. Low-intensity spots (arrows) correspond to punctate lesions. C, R2* shows high signal in the punctate white matter lesions (arrows). D, QSM shows high signal at the punctate white matter lesions (arrows). E-H, Focal hemorrhagic lesions in a preterm neonate born at 35 weeks' gestational age, scanned at 38 weeks' gestational age (corresponding to case 6 in Table 3). E, T1-weighted axial image shows isolated high-intensity spots (arrows) corresponding to focal hemorrhagic lesions in the bilateral cerebellar hemispheres. F, Corresponding T2-weighted axial image. Low-intensity spots (arrows) correspond to focal hemorrhagic lesions, $G$ and $H, 2^{*}$ and QSM, respectively, show very high signal at the focal hemorrhagic lesions (arrows), indicative of paramagnetic hemorrhagic products. I-L, Punctate white matter lesions in a preterm neonate born at 31 weeks' gestational age, scanned at 37 weeks' gestational age (corresponding to case 3 in Table 3). T1-weighted axial image (I), T2-weighted axial image (I), R2* (K), and QSM (L) through the body of the lateral ventricles show more punctate white matter lesions than the above term neonates in the 2 hemispheres (arrows). Lesions are linearly organized in the periventricular white matter.

various tissues, such as the liver, heart, and brain. ${ }^{33,36}$ On the other hand, our data suggest that $\mathrm{R} 2{ }^{\star}$ best distinguishes healthy white matter and PWMLs (see subject 7 in Fig 2 and the boxplots in Fig 3).

While QSM studies have often used well-characterized tissue as a reference to scale susceptibility values, such as CSF in the ventricles, recent studies have reported insignificant differences between raw and reference-normalized QSM. ${ }^{37}$ To avoid making basic assumptions inherent in normalization, we decided to report raw values here.

Histologic and MR imaging studies suggest that PWMLs result in intense macrophage and microglial infiltration and reduced astroglia, which coincide with microscopic necrosis and early gliosis. ${ }^{10,11}$
What components in these lesions lead to faster $\mathrm{T}^{*}$ signal decay and increased magnetic susceptibility? Is there an increase in iron content within PWMLs? ${ }^{38}$ More histopathologic studies would be welcome. While iron can also be expected to be present in macrophages as hemosiderin deposits in the PWMLs, the lesions classified as focal hemorrhage might, as well, arise from a PWML, which has been hemorrhagically transformed. Of course, many focal hemorrhagic lesions are expected to be excluded from being falsely identified as PWMLs, but there might be an unknown proportion of actual PWMLs that have transformed hemorrhagically and are excluded from being further analyzed as PWMLs though they might be relevant according to disease outcome. 

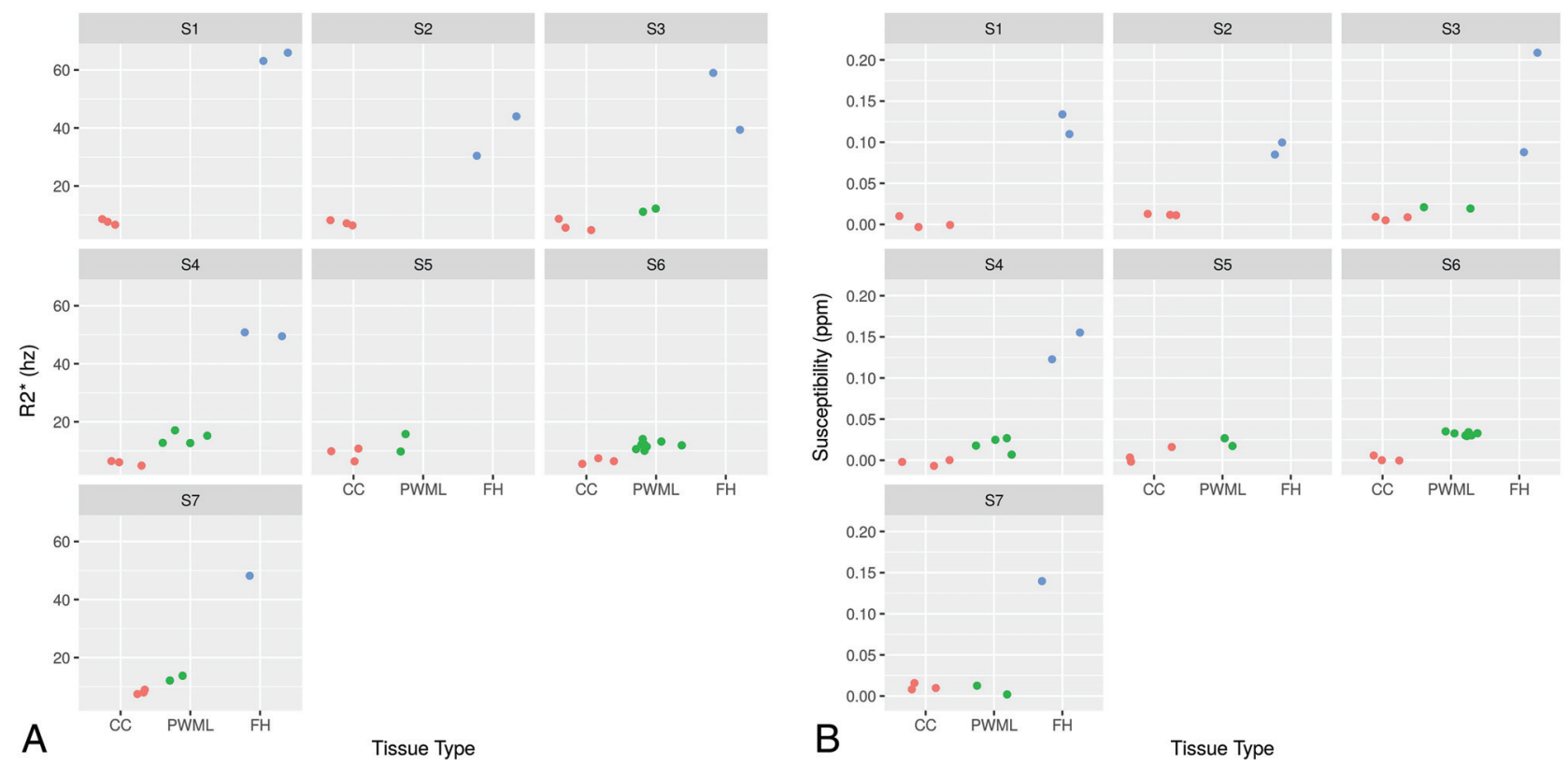

FIG 2. The R2* $(A)$ and susceptibility $(B)$ values for the 3 tissue/lesion types for each subject (S1-S7).
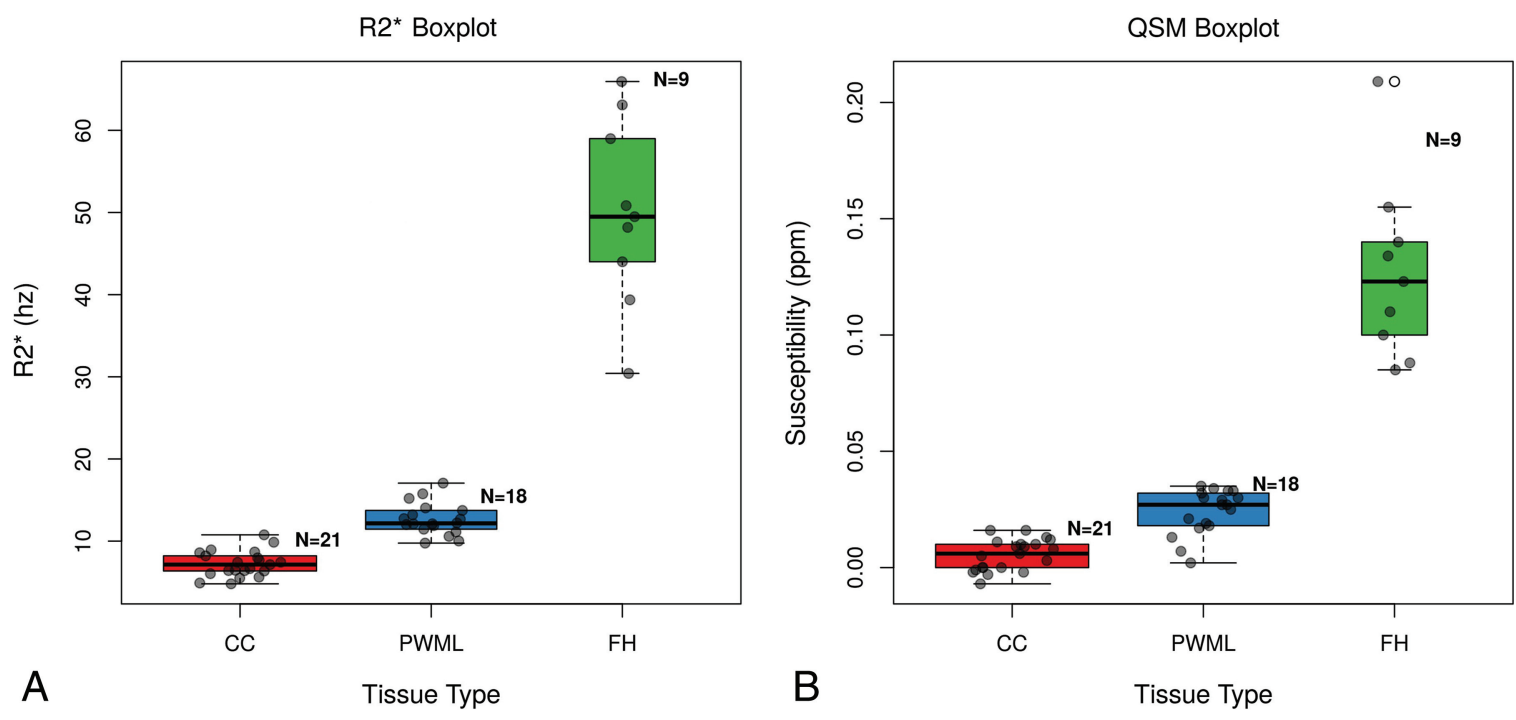

FIG 3. Boxplots of $R 2^{*}(A)$ and susceptibility $(B)$ values for the 3 tissue/lesion types.

Table 4: The mean and SD of R2* and susceptibility in 3 groups

\begin{tabular}{lccc}
\hline \multicolumn{1}{c}{ ROls } & CC & PWMLs & FH \\
\hline R2 $^{*}(\mathrm{~Hz})$ & $7.23 \pm 1.57$ & $12.65 \pm 1.94$ & $50.04 \pm 11.42$ \\
Susceptibility $(\mathrm{ppm})$ & $0.0054 \pm 0.0067$ & $0.024 \pm 0.010$ & $0.127 \pm 0.039$ \\
\hline
\end{tabular}

Note:-CC indicates corpus callosum; FH, focal hemorrhagic lesion.

\section{CONCLUSIONS}

$\mathrm{R} 2 *$ relaxation and QSM can be used to distinguish PWMLs from focal hemorrhagic lesions and may be used as quantitative predictive tools to evaluate the correlation between PWMLs and neurodevelopmental outcomes in future studies.

\section{REFERENCES}

1. Horbar JD, Badger GJ, Carpenter JH, et al; Members of the Vermont Oxford Network. Trends in mortality and morbidity for very low birth weight infants, 1991-1999. Pediatrics 2002;110(1 Pt 1):143-51 CrossRef Medline
2. van den Hout BM, de Vries LS, Meiners LC, et al. Visual perceptual impairment in children at 5 years of age with perinatal haemorrhagic or ischaemic brain damage in relation to cerebral magnetic resonance imaging. Brain Dev 2004;26:251-61 CrossRef Medline

3. Grunau RE, Whitfield MF, Davis C. Pattern of learning disabilities in children with extremely low birth weight and broadly average intelligence. Arch Pediatr Adolesc Med 2002;156:615-20 CrossRef Medline

4. Hamrick SE, Miller SP, Leonard C, et al. Trends in severe brain injury and neurodevelopmental outcome in premature newborn infants: the role of cystic periventricular leukomalacia. J Pediatr 2004;145:593-99 CrossRef Medline

5. Maalouf EF, Duggan PJ, Counsell SJ, et al. Comparison of findings on cranial ultrasound and magnetic resonance imaging in preterm infants. Pediatrics 2001;107:719-27 CrossRef Medline

6. Inder TE, Anderson NJ, Spencer C, et al. White matter injury in the premature infant: a comparison between serial cranial sonographic and MR findings at term. AJNR Am J Neuroradiol 2003;24:805-09 Medline 
7. Inder TE, Wells SJ, Mogridge NB, et al. Defining the nature of the cerebral abnormalities in the premature infant: a qualitative magnetic resonance imaging study. J Pediatr 2003;143:171-79 CrossRef Medline

8. Miller SP, Cozzio CC, Goldstein RB, et al. Comparing the diagnosis of white matter injury in premature newborns with serial MR imaging and transfontanel ultrasonography findings. AJNR Am J Neuroradiol 2003;24:1661-69 Medline

9. Debillon T, N'Guyen S, Muet A, et al. Limitations of ultrasonography for diagnosing white matter damage in preterm infants. Arch Dis Child Fetal Neonatal Ed 2003;88:F275-79 CrossRef Medline

10. Schouman-Claeys E, Henry-Feugeas MC, Roset F, et al. Periventricular leukomalacia: correlation between MR imaging and autopsy findings during the first 2 months of life. Radiology 1993;189:59-64 CrossRef Medline

11. Riddle A, Dean J, Buser JR, et al. Histopathological correlates of magnetic resonance imaging-defined chronic perinatal white matter injury. Ann Neurol 2011;70:493-507 CrossRef Medline

12. Jeon TY, Kim JH, Yoo SY, et al. Neurodevelopmental outcomes in preterm infants: comparison of infants with and without diffuse excessive high signal intensity on MR images at near-term-equivalent age. Radiology 2012;263:518-26 CrossRef Medline

13. Miller SP, Ferriero DM, Leonard C, et al. Early brain injury in premature newborns detected with magnetic resonance imaging is associated with adverse early neurodevelopmental outcome. J Pediatr 2005;147:609-16 CrossRef Medline

14. Dyet LE, Kennea N, Counsell SJ, et al. Natural history of brain lesions in extremely preterm infants studied with serial magnetic resonance imaging from birth and neurodevelopmental assessment. Pediatrics 2006;118:536-48 CrossRef Medline

15. Cornette LG, Tanner SF, Ramenghi LA, et al. Magnetic resonance imaging of the infant brain: anatomical characteristics and clinical significance of punctate lesions. Arch Dis Child Fetal Neonatal Ed 2002;86:F171-77 CrossRef Medline

16. Keeney SE, Adcock EW, McArdle CB. Prospective observations of 100 high-risk neonates by high-field (1.5 Tesla) magnetic resonance imaging of the central nervous system, II: lesions associated with hypoxic-ischemic encephalopathy. Pediatrics 1991;87: 431-38 Medline

17. Baenziger O, Martin E, Steinlin M, et al. Early pattern recognition in severe perinatal asphyxia: a prospective MRI study. Neuroradiology 1993;35:437-42 CrossRef Medline

18. Battin MR, Maalouf EF, Counsell SJ, et al. Magnetic resonance imaging of the brain in very preterm infants: visualization of the germinal matrix, early myelination, and cortical folding. Pediatrics 1998;101:957-62 CrossRef Medline

19. Mercuri E, Rutherford M, Cowan F, et al. Early prognostic indicators of outcome in infants with neonatal cerebral infarction: a clinical, electroencephalogram, and magnetic resonance imaging study. $P e-$ diatrics 1999;103:39-46 CrossRef Medline

20. Ramenghi LA, Fumagalli M, Righini A, et al. Magnetic resonance imaging assessment of brain maturation in preterm neonates with punctate white matter lesions. Neuroradiology 2007;49:161-67 CrossRef Medline

21. Cheng I, Miller SP, Duerden EG, et al. Stochastic process for white matter injury detection in preterm neonates. Neuroimage Clin 2015; 7:622-30 CrossRef Medline

22. Niwa T, de Vries LS, Benders MJ, et al. Punctate white matter lesions in infants: new insights using susceptibility-weighted imaging. Neuroradiology 2011;53:669-79 CrossRef Medline

23. Gano D, Andersen SK, Partridge JC, et al. Diminished white matter injury over time in a cohort of premature newborns. J Pediatr 2015; 166:39-43 CrossRef Medline

24. Yablonskiy DA, Haacke EM. Theory of NMR signal behavior in magnetically inhomogeneous tissues: the static dephasing regime. Magn Reson Med 1994;32:749-63 CrossRef Medline

25. Deistung A, Schweser F, Reichenbach JR. Overview of quantitative susceptibility mapping. NMR Biomed 2017;30 CrossRef Medline

26. Denk C, Rauscher A. Susceptibility weighted imaging with multiple echoes. J Magn Reson Imaging 2010;31:185-91 CrossRef Medline

27. Schofield MA, Zhu Y. Fast phase unwrapping algorithm for interferometric applications. Opt Lett 2003;28:1194-96 CrossRef Medline

28. Li W, Wu B, Liu C. Quantitative susceptibility mapping of human brain reflects spatial variation in tissue composition. Neuroimage 2011;55:1645-56 CrossRef Medline

29. Kames C, Wiggermann V, Rauscher A. Rapid two-step dipole inversion for susceptibility mapping with sparsity priors. Neuroimage 2018;167:276-83 CrossRef Medline

30. Koo TK, Li MY. A guideline of selecting and reporting intraclass correlation coefficients for reliability research. J Chiropr Med 2016; 15:155-63 CrossRef Medline

31. Mori N, Miki Y, Kikuta K, et al. Microbleeds in moyamoya disease susceptibility-weighted imaging versus $\mathrm{T} 2^{\star}$-weighted imaging at 3 Tesla. Invest Radiol 2008;43:574-79 CrossRef Medline

32. Nandigam RN, Viswanathan A, Delgado P, et al. MR imaging detection of cerebral microbleeds: effect of susceptibility-weighted imaging, section thickness, and field strength. AJNR Am J Neuroradiol 2009;30:338-43 CrossRef Medline

33. Wang Y, Spincemaille P, Liu Z, et al. Clinical quantitative susceptibility mapping (QSM): biometal imaging and its emerging roles in patient care. J Magn Reson Imaging 2017;46:951-71 CrossRef Medline

34. Barbosa JH, Santos AC, Tumas V, et al. Quantifying brain iron deposition in patients with Parkinson's disease using quantitative susceptibility mapping, R2 and R2. Magn Reson Imaging 2015;33: 559-65 CrossRef Medline

35. Liu T, Eskreis-Winkler S, Schweitzer AD, et al. Improved subthalamic nucleus depiction with quantitative susceptibility mapping. Radiology 2013;269:216-23 CrossRef Medline

36. Sharma SD, Fischer R, Schoennagel BP, et al. MRI-based quantitative susceptibility mapping (QSM) and $\mathrm{R}^{*}$ mapping of liver iron overload: comparison with SQUID-based biomagnetic liver susceptometry. Magn Reson Med 2017;78:264-70 CrossRef Medline

37. Acosta-Cabronero J, Betts MJ, Cardenas-Blanco A, et al. In vivo MRI mapping of brain iron deposition across the adult lifespan. $\mathrm{J} \mathrm{Neu-}$ rosci 2016;36:364-74 CrossRef Medline

38. Meguro R, Asano Y, Odagiri S, et al. Cellular and subcellular localizations of nonheme ferric and ferrous iron in the rat brain: a light and electron microscopic study by the perfusion-Perls and -Turnbull methods. Arch Histol Cytol 2008;71:205-22 CrossRef Medline 